\title{
Commentary
}

\section{After Fourteen Years the OECD NCP of The Netherlands Serves Justice for 168 Workers who have been Wronged during Times of Civil War} By Yvonne Erkens, Associate Professor of Labour Law, Leiden University, The Netherlands

\section{Introduction}

Heineken N.V. is a multinational enterprise based in Amsterdam; Bralima is a subsidiary of Heineken N.V. Since 1987 Heineken has directly held approximately 95 percent of Bralima's shares. Bralima has been operating in the Democratic Republic of the Congo (DRC) for more than ninety years.

The Dutch National Contact Point (NCP) for the OECD Guidelines for Multinational Enterprises received a complaint from Namegabe Bugabo, Matabaro Rubanza, and Bayongwa Mirimba, former employees of Bralima and formally accepted by the NCP as representatives of a group of approximately 168 former employees. The complaint stated that these employees were dismissed between 1999 and 2003. The notification concerns allegations regarding unjustified dismissal of 168 Bralima employees between 1999 and 2003, irregularities and deliberate omissions in the individual redundancy schemes for dismissed workers and serious errors in the mass dismissals by Bralima between 1999 and 2003 - all contrary to Congolese law. Furthermore, these dismissals were authorized not by a competent authority, as required by law, but instead by the rebel movement RCD-Goma. RCD-Goma's approval, however, does not give the dismissals any legitimacy. The complainants stated that Bralima took advantage of a period of economic and political turmoil in the DRC to dismiss a large number of employees in a short time without 
providing the basic guarantees required by Congolese and international law, and that the employees thus dismissed were replaced by temporary workers. The notification specifically concerned the alleged non-observance of the 2000 version of the OECD Guidelines for Multinational Enterprises, Chapter 1 Concept and Principles, Chapter II General policies, Chapter v Employment and Industrial Relations and Chapter vi Combating Bribery. For that Bralima and Heineken should pay $€_{200}$ million in compensation to the former employees and their families.

The Guidelines are applicable to Heineken because it is a Dutch multinational enterprise. However, because the events occurred between 1999 and 2003 , the 2000 version of the Guidelines applies and not the 2011 version. The 2000 Guidelines do not mention enterprise groups, but do refer to business partners and state that the enterprise should encourage them, where practicable, to apply principles of corporate conduct compatible with the Guidelines. The NCP therefore concluded that the Guidelines apply equally to Bralima, being a 95 percent subsidiary of Heineken, which implies a strong business partner relationship. The Heineken business conduct framework has been implemented worldwide at all companies within the Heineken Group, including Bralima, setting out the principles and core values that all employees worldwide need to observe.

Starting with the publication of its initial assessment on 28 June 2016, the NCP took several intermediate steps - including dialogue roundtables held in neutral territory outside the DRC - to reach its final statement in August 2017.

The OECD procedural guidance for NCPS stipulates that information on the content of the agreement will be included in the final statement only insofar as the parties involved agree. In this specific instance, the parties wished to maintain confidentiality on the agreement and the outcome. Open discussions during an NCP process under protection of confidentiality are therefore impossible, but also mean that not all lessons learned from a case can be shared with other NCPs and stakeholders.

The NCP concludes that all parties participated in the process in a proper and fair way and that several lessons have been learned from this specific instance. Because each side already had a good relationship with the NCP, and the NCP participated, both the former employees and Bralima/Heineken had the confidence to talk with each other. The (expert) mediator bridged the gap between the complainants and generated additional relevant information. By accessing and responding to the mediator before the roundtable meetings, the parties were prepared for the dialogue. 


\section{Analysis}

The specific instance concerns a period of four years (1999 to 2003), during which time violent conflict in the DRC was ongoing. Bralima is one of the largest producers of beer and soft drinks in the DRC and, as such, has significant economic and social impact. It decided to stay in the country despite the deteriorating economy. The NCP notes that operating in volatile and conflict-affected countries is complex and may lead to difficult situations and choices. As the UN, the OECD and the World Bank also point out, leaving conflict-affected countries reduces economic opportunities and contributes to a poverty-conflict trap.

In its initial assessment, the NCP stated that the consideration of this specific instance did not entail substantive research or fact-finding on the individual cases and that the NCP procedure is not a judicial procedure but a mediation procedure aimed at reaching an agreement on the issue at stake. The NCP can make recommendations in the light of the Guidelines, but cannot decide on financial compensation.

Both parties accepted the NCP's offer to initiate a dialogue and requested the appointment of a third-party mediator. In most cases, NCP members facilitate the mediation sessions, but here the NCP appointed an expert mediator with considerable experience and knowledge of the situation in the region. After the mediation dialogues ended in January 2017, Heineken engaged an expert in the field of Congolese law, who was approved by the NCP.

Confidential information disclosed to the NCP is not used in preparing the final statement, which is an advantage for employers, who, understandably, want to protect their secrets, business or other. A corollary benefit is that the information on which the final statement is based also stays out of sight. It are the parties involved with the specific instance that determine what information is confidential and what is public. This is an important aspect of why parties voluntarily accept to participate in the procedure of the NCP. As a result, NCP jurisprudence is a limited source of information or precedent for subsequent cases.

The goal of the dialogue between parties was not only to resolve the issues raised in the specific instance but also to formulate recommendations for improving implementation of the current Guidelines. For the future, Heineken has indicated that it will draw up a policy and practice document on how to conduct business that will address the employment process from recruitment to termination, operating in a conflict-affected environment, and procedural issues in relations between operating companies and headquarters. 


\section{Conclusions}

This specific instance relates to facts and circumstances of more than fourteen years ago, which made it difficult to retrieve all relevant information. Another obstacle was that it relates to a difficult time - civil war - within the DRC. As mentioned, a dilemma for multinational companies arises when a country becomes involved in an armed conflict: staying in the area often means being forced to operate within a power vacuum, leaving can have dramatic and negative consequences for the company as well as for its employees and the economy of the country.

Bralima and Heineken stated that the minimum legal requirements for compensation on departure were upheld for all employees who left, and that any errors in calculating them were inadvertent. The decision to remain operative in a conflict-affected area entails its own challenges and dilemmas. As far as Bralima and Heineken are concerned, no indications were found of cooperation with RCD-Goma, or of human rights violations or of non-observance of the Guidelines. At the same time, however, the employees alleged that Bralima used the civil war to secure permission - contrary to Congolese law - from the rebel movement RCD-Goma for the mass dismissals.

Because the parties invoked confidentiality, which statement is true and to what extent remains unclear. Any conclusions would be premature, but it is striking that the NCP recommends that transparency and communication to employees be part of enterprises' policies for dealing with conflict settings. The NCP also recommends that the handling of complaints by current or former employees should be monitored and evaluated within company groups. Media reports that Heineken paid \$1.3 million to the 168 dismissed employees. The brewery, however, did not confirm that any compensation had been paid. 